\title{
Ranchers and Biologists in Hawai ' $i$-Keeping a Business Strong and Protecting Native Forests at Ulupalakua Ranch, Maui
}

\author{
Sumner Erdman, Arthur Medeiros, Anthony Durso, and Lloyd Loope
}

$\mathrm{T}$ The loss of ranchland to critical habitat has been a major concern to ranchers and other large landowners in recent years. On the island of Maui, a novel approach is in the works which seems to have merit both for conservation of endangered species and for helping a landowner ethically manage an ecologically sensitive area.

\section{Ulupalakua Ranch's Critical Environment}

Perched on the high, dry southwestern slopes of Haleakala volcano on Maui, Ulupalakua Ranch contains the type of heart-stopping views, ecological amplitude, and biological diversity more commonly found in national parks than on ranches. Stretching from sea level to an elevation of 6,000 feet, the ranch contains examples of no less than eight major vegetation communities, impressive considering its relatively small size of 23,000 acres. The Ranch currently supports populations of two animal and nine plant species listed as endangered species by the U.S. Fish and Wildlife Service (FWS) as well as many very rare native plants and animals which may be listed in the future.

Maui and the rest of the Hawaiian Islands represent an evolutionary showcase. The plants and animals which reached these islands through long-distance dispersal evolved in isolation on this remote archipelago for millions of years. The Hawaiian honeycreepers among birds and the silversword alliance among plants are species-rich groups which provide classic, textbook examples of evolutionary adaptive radiation from a single common ancestral population. Sadly, the Hawaiian islands also provide an all too excellent example of the devastating impacts of habitat destruction and alteration through introduction of invasive plant and animal species by humans. The occurrence of over 300 plant and animal species in Hawai'i (about one-third of the total nationwide, in twotenths of $1 \%$ of the total land area) listed as endangered species by FWS represent a poignant symptom of the destruction and alteration through invasion.

A major societal challenge in the U.S. for the $21^{\text {st }}$ century involves developing strategies to maintain biological diversity, especially in such vulnerable areas as Hawai' $i$, in an age of increasing population, globalization, and homogenization. Making this challenge all the more daunting, is the fact that these vulnerable habitats are often located on the property of economically strapped landowners. One of the most promising projects in the state of Hawai' $i$, perhaps comprising a prototype for progress toward meeting these challenges, is a growing partnership between Ulupalakua Ranch, funding sources, and conservation agencies. Here we explore the long-range potential of an incipient partnership effort on Ulupalakua Ranch.

\section{The Rancher's Perspective:}

Located in an economically struggling and ecologically sensitive area, Ulupalakua Ranch strives to balance its efforts to maintain a productive cattle operation and support Maui's agricultural industry with its interests in protecting Maui's environment. Traditionally, the Ranch has focused on beef production and currently runs 3,600 head of cattle, mostly Angus, Brangus, and Hereford. The drought and market woes known to all ranchers forced Ulupalakua to look for alternative sources of revenue and to open more pastures. The Ranch now maintains a herd of approximately 150 Rocky Mountain elk for velvet and exotic meat production and leases land to local farmers. Other on-going ventures include recreational and educational tours and paid game bird and axis deer hunts. Furthermore, it has fenced and installed water troughs in previously unused or little used areas.

In diversifying its income and increasing its pastures, the Ranch stumbled into a new set of problems. Those lands on which the tours take place and cattle graze are near the homes of some of Hawaii's endangered and rare species. Historically, the relationship between private landowners and conservationists has been adversarial. Consequently, these groups have battled with each other, to both their detriment at considerable cost. Unable to afford to lose such a battle, troubled by the waste inherent in this dynamic, and genuinely supportive of preserving native species, the Ranch prefers to solicit federal, state, and county cost-share funding for conservation programs and work closely with their agents to support economically sound and environmentally safe use of the land. The resulting construction of a greenhouse for native plants, the protection of forest areas for preservation and propagation of those plants, and an increase in and improvement of pastureland testify to the merits of this more cooperative strategy.

One of the featured projects is the dryland forest of Auwahi (Figure 1). Located in a remote area of the Ranch, Auwahi is just one of five current large-scale projects related to conservation of biodiversity, endangered species, and watershed protection. Supported by the Ranch, a multiplicity of federal, state and county government agencies, and local and national charitable organizations, these projects utilize seed collection and propagation, progressive fencing and grazing techniques, aggressive manual and chemical weed management, and community education to achieve goals. Thanks to the lasting commit- 


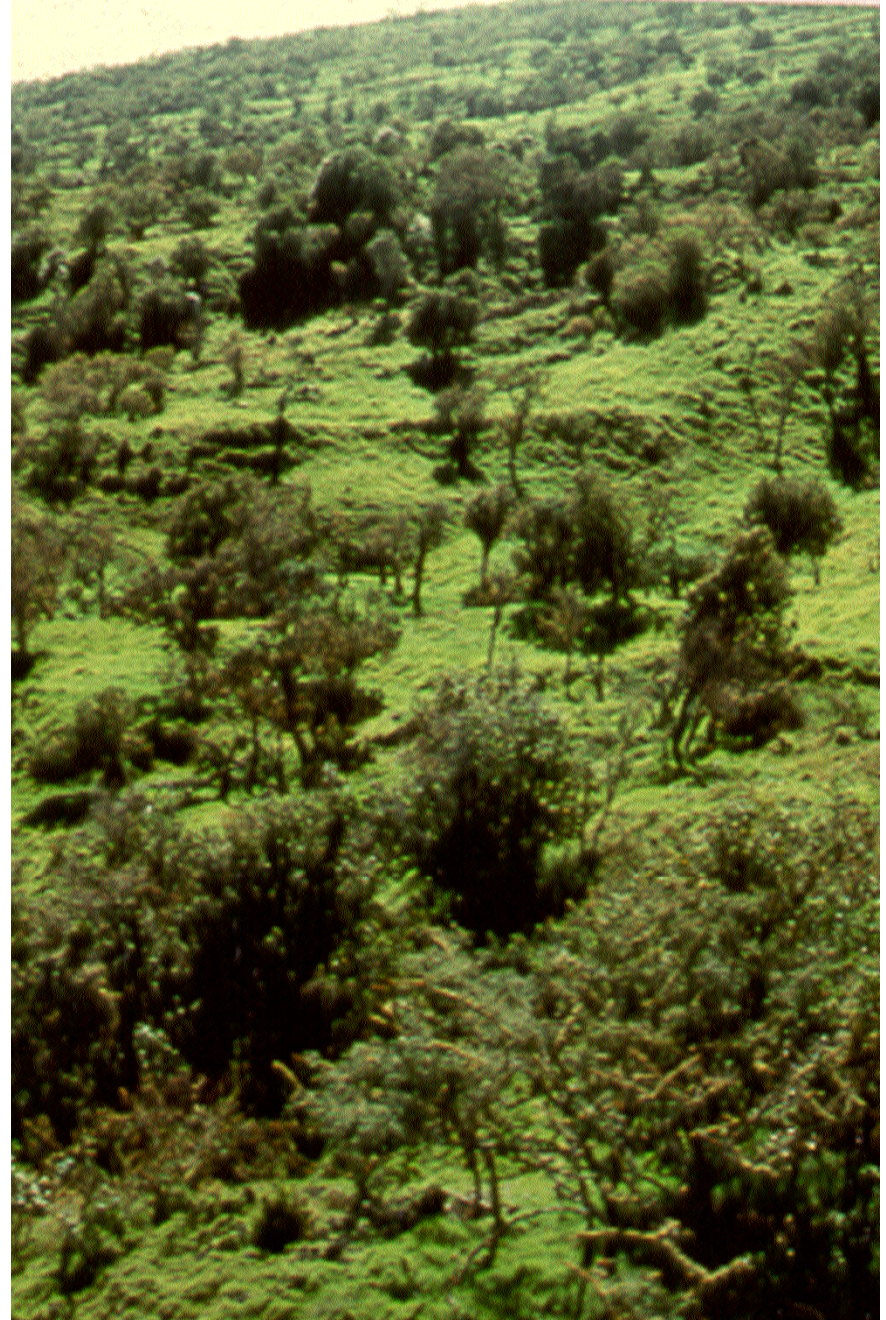

Fig. 1. Remnant dryland forest at Auwahi, Ulupalakua Ranch, Maui, eleva tion 4,000 ft.

ment and continuous effort of everyone involved, the success of these projects has exceeded initial expectations.

In the future, it is the Ranch's hope that its conservation efforts can be fully combined with its livestock operation and visitor activities. By showing that tightly controlled grazing can help control invasive plants around critical habitats, the Ranch hopes to maintain access to its pastures as well as protect endangered species. Furthermore, tours of native plant gardens and forests could provide Maui visitors with a completely unique opportunity to see and learn about some of Hawaii's most rare plants as well as one of Hawaii's most interesting forest types. The beauty of this plan is that the environment will be preserved and the Ranch will become more stable economically...a true symbiosis.

\section{The Biologist's Perspective}

Dryland forests are among the most threatened of Hawaiian ecosystems. On Maui, only an estimated $4 \%$ of the original dryland forest still remains. Auwahi, with a very high diversity of native tree species, is generally considered one of the most intact dryland forest areas in the state (Wagner et al.
1990). The area was first explored botanically in the early $20^{\text {th }}$ century by Joseph Rock of University of Hawai ' $i$ and Charles Forbes of Bishop Museum. In his famous book Indigenous Trees of the Hawaiian Islands (1913), Rock praised the area for its botanical diversity calling it one of the richest districts in the State. Upon his return to the area some 20 years later in 1939, Rock is said to have wept over the dramatic deterioration during his absence.

The first attempts at conservation at Auwahi were made in the late 1960s, when retired Territorial Forester Colin Lennox and The Nature Conservancy constructed a large exclosure in an abortive restoration effort which unfortunately coincided with the invasion of the area by kikuyu grass (Pennisetum clandestinum). USGS scientists (with National Park Service until 1993) began exploratory work, with the permission (and blessing) of the landowner, Ulupalakua Ranch, 19 years ago. A status report based on extensive field exploration in the early 1980s (Medeiros et al. 1986) called attention to continued deterioration of native vegetation on leeward Haleakala and identified the Auwahi area as a prime area worthy of concerted conservation efforts.

Reasons for lack of reproduction may be complex and overlapping but probably include browsing by domestic cattle and digging by feral pigs; displacement by the aggressive introduced tropical African pasture grass, kikuyugrass, and microclimate change. Our observations suggest that with protection from ungulate browsing and digging, removal of the kikuyugrass mat, and restoration of favorable microhabitat, dryland forest restoration can be achieved at Auwahi.

The diverse forest continues to decline due to the absence of seedlings and saplings. For many species, reproduction by seed may not have occurred for a period of 50 to several hundred years. We have seen seedlings and saplings in the field for only 12 of 50 tree species at Auwahi over a 19-year period of field observations. Despite this, at least 36 species can be germinated and grown in greenhouse conditions. Of native trees found at Auwahi, six are listed by FWS as endangered species, five have been considered "species of concern," and many of the others are rare and declining range-wide.

Ethnobotanically, these forests were invaluable to early Hawaiians (Medeiros et al. 1999). Of the 50 tree species found here, 41 had specific uses. Nineteen species were used in medicines, 13 in making specific tools, 13 in canoe construction, eight in making bark cloth, eight to make dyes ranging from pink to blue to a rich yellow-orange. At least seven species have spiritual significance and were used in religious and cultural ceremonies. Other miscellaneous uses ranged from fireworks, to bird lime, to a fish narcotizing agent. There is tremendous interest within both the Hawaiian conservation community and the native Hawaiian community in restoring tracts of dryland forest. However, to date there are no major success stories for dryland forest restoration in Hawai ${ }^{i}$.

Assisted by past funding from FWS, USGS has located one of the richest tracts of Auwahi for restoration, fenced a prime 10.4 acre site for experimental restoration (elevation 4,000 ft), and has initiated a greenhouse propagation and outplanting program with assistance of funds provided directly to the 
landowner by FWS. We presented a conceptual plan for 120 acres of Auwahi restoration at the Hawai' $i$ Conservation Conference in July 1997 with landowner approval. The plan involves replacing the kikuyugrass cover among the museumpiece trees with a "nurse forest" of quick-growing native trees to create relatively moist, semi-shaded microhabitat in which dryland forest seedlings can become established and flourish (Figure 2). A relatively brief window of opportunity exists during which this declining dryland forest is relatively restorable. Though forest decline is at a relatively advanced stage, excellent seed sources for most species still exist.

Currently, we are in the midst of implementing an experimental USGS-funded research project to develop methodology for establishing a nurse forest of native shrubs/trees to secure the site from weed invasion and eventually (within several years) provide habitat for restoration of 50 tree species. Based on the results of this project, the most effective methodology would be used as soon as funding for management could be obtained (from FWS and other sources) to restore dryland forest on additional Auwahi land, up to the 120 acres

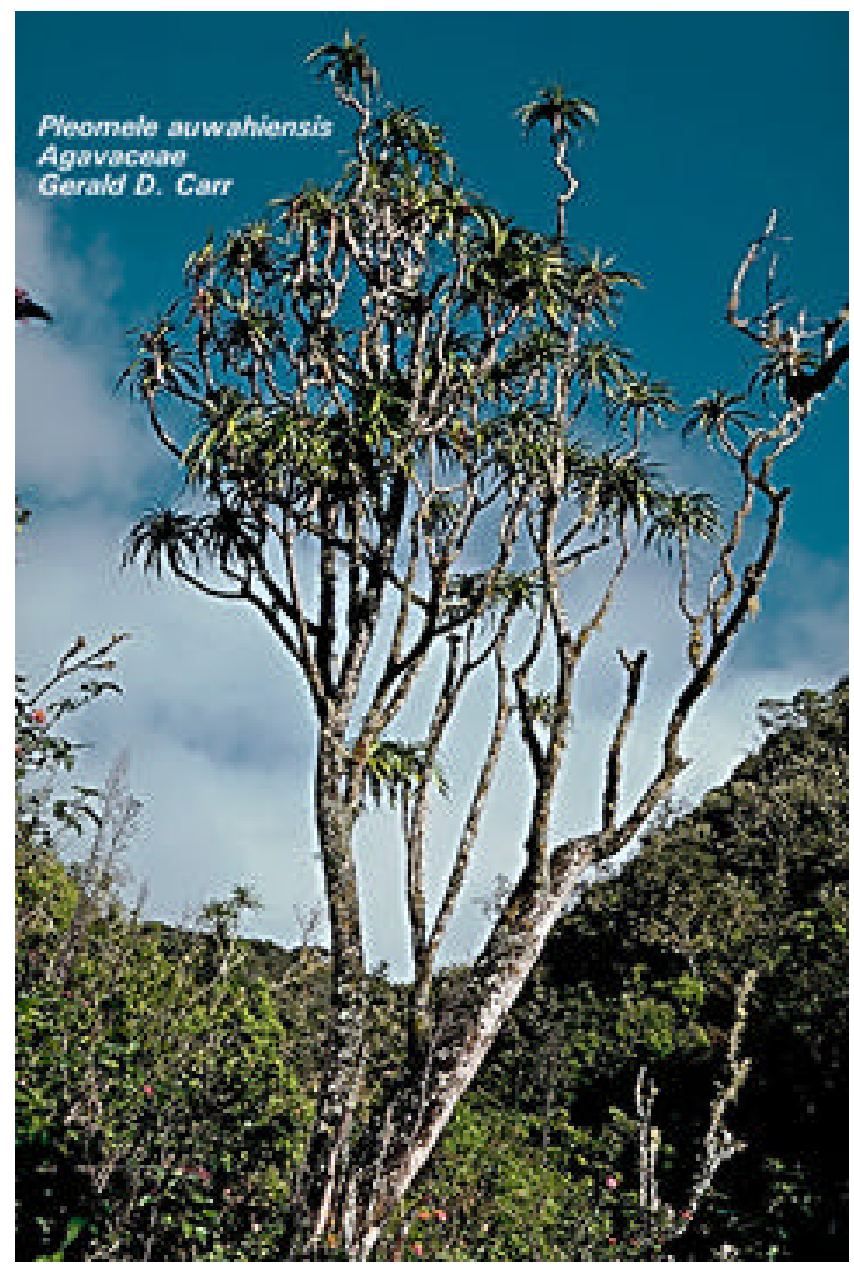

Fig. 2. Halapepe (Pleomele auwahiensis St. John) in the Agave family is one of the dominant species in remnant dryland forests at Auwahi, but almost no natural regeneration has been seen recently. Several hundred experimental halapepe seedlings were planted at Auwahi in January 2000. to which the landowner has willingly agreed. Based on methods developed through our ongoing pilot project, we can soon feel confident in our ability to cooperatively restore and manage dryland forest at Auwahi.

\section{References Cited}

Medeiros, A.C., L.L. Loope, and R.A. Holt. 1986. Status of native flowering plant species on the south slope of Haleakala, East Maui, Hawai 'i. Coop. Natl. Park Resources Studies Unit, Univ. Hawai'i, Technical Report 59.

Medeiros, A.C., C.F. Davenport, and C.G. Chimera. 1999. Auwahi: ethnobotany of a Hawaiian dryland forest. Coop. Natl. Park Resources Stud. Unit, Univ. Hawai ‘i, Technical Report 117.

Rock, J.F. 1913. The indigenous trees of the Hawaiian Islands. Publ. privately, Honolulu (Reprinted with addendum in 1974, Charles E. Tuttle Co., Rutland, Vt..)

Wagner W.L., D.R. Herbst, and S.H. Sohmer. 1990 Manual of the flowering plants of Hawai'i. University of Hawai' $i$ Press and Bishop Museum Press, Honolulu, Hawaii

Sumner Erdman is an owner, and both Sumner and Tony Durso help manage Ulupalakua Ranch. Arthur Medeiros and Lloyd Loope are biologists with the United States Geological Survey (USGS), Biological Resources Division, based at the Haleakala National Park Field Station on Maui.

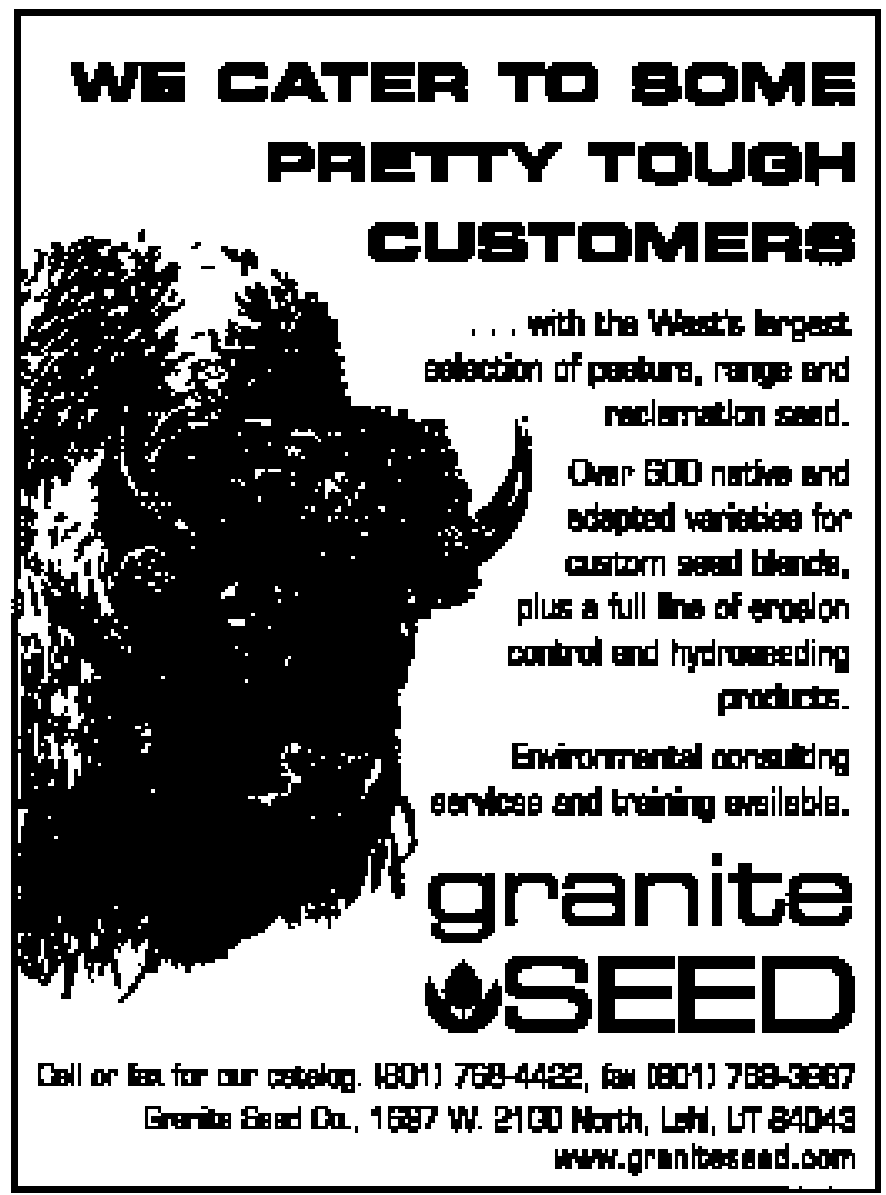

